\title{
Analysis on the Evolution Trend of Seawater Quality and Eutrophication in Tianjin Hangu Agricultural and Fishery Area from 2010 to 2019
}

\author{
Yi Chen ${ }^{1, \mathrm{a}}$ \\ ${ }^{1}$ TIANJIN RESEARCH INSTITUTE FOR WATER TRANSPORT ENGINEERING, M.O.T.
}

\begin{abstract}
Through the collection and analysis of COD, dissolved inorganic nitrogen (DIN) and active phosphate monitoring data in Tianjin Hangu Agricultural and fishery area from 2010 to 2019, this paper analyzed and studied the structure of nutrients and the state of eutrophication. The results show that in recent ten years, the water quality of Tianjin Hangu Agricultural and Fishery Area has basically met the water quality requirements of functional area, the regional nitrogen pollution has been suppressed, and the eutrophication index of sea area has shown a decreasing trend year by year, but the nitrogen and phosphorus nutrient structure is still in the state of "phosphorus restriction". Pollution control of sea areas and conservation of aquatic germplasm resources are still urgent.
\end{abstract}

\section{Introduction}

Tianjin Hangu Agricultural and Fishery Area is located on the top of the semi-enclosed Bohai Bay, the seawater dynamic conditions are poor, the sea area pollutants are easy to accumulate locally and the self-purification capacity is very limited. The main pollution factors in Bohai Bay are inorganic nitrogen and phosphorus and the main sources of pollution are the river catchment, the sea sewage outlet, port ships and marine aquaculture. In Bohai Bay, the area near Beitang where concentrated the Jiyun River, Yongding New River, Chaobai New River and other rivers flowing into the sea is a high-pollution area, and the main source is land-based sewage.

In order to expand the agricultural development space and develop marine biological resources, Tianjin Municipal People's Government has designated three agricultural and fishery areas in the 《Tianjin Marine Functional Zoning (2011 2020)》. Among them, Hangu Agricultural and Fishery Zone is located near Beitang sea area, as shown in Figure 1, is suitable for aquaculture and fishery infrastructure, prohibit new sewage outlets, in order to protect important aquatic germplasm resources and their habitats, the water quality standard is not inferior to Class II.

This paper selects the monitoring results of COD, dissolved inorganic nitrogen (DIN) and active phosphate in the Hangu Agricultural and Fishery Area in the past 10 years (2010-2019) to evaluate and analyze the regional variations of organic matter, nutrients and eutrophication status.

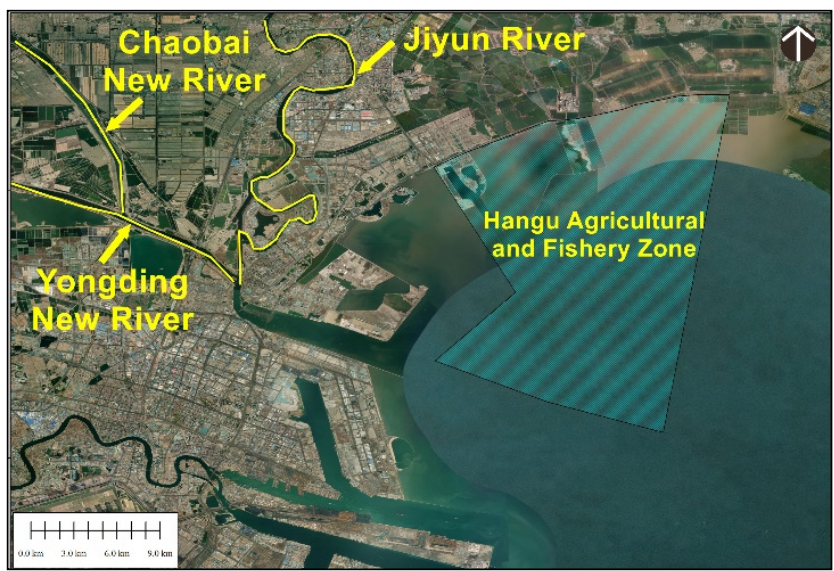

Fig. 1. Hangu Agricultural and Fishery Area and nearby rivers entering the sea.

\section{Historical data collection and analysis}

\subsection{Monitoring stations and factors}

Select spring Monitoring data in Hangu Agricultural and Fishery Area from 2010-2019 to evaluate and analyze the varying tendency of COD, DIN and active phosphate. The monitoring stations are shown in Figure 2 to Figure 4. 


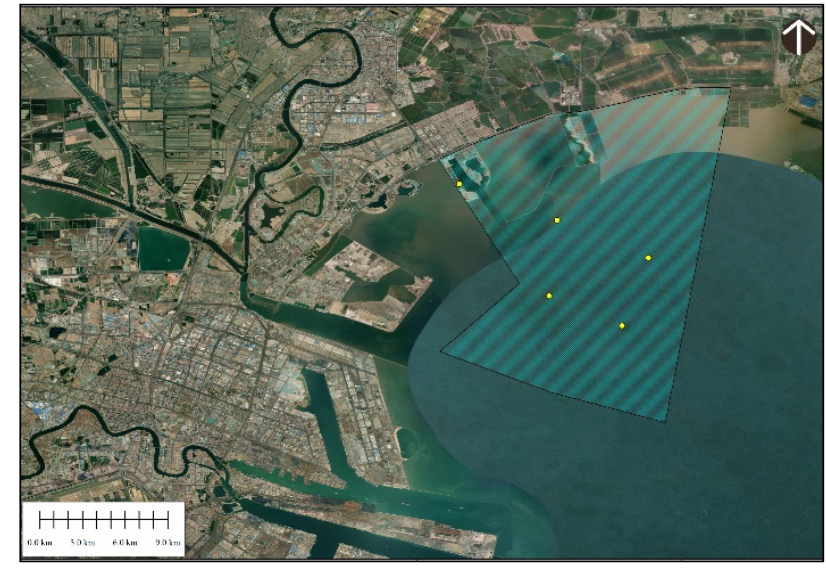

Fig. 2. Monitoring stations from 2010 to 2015.

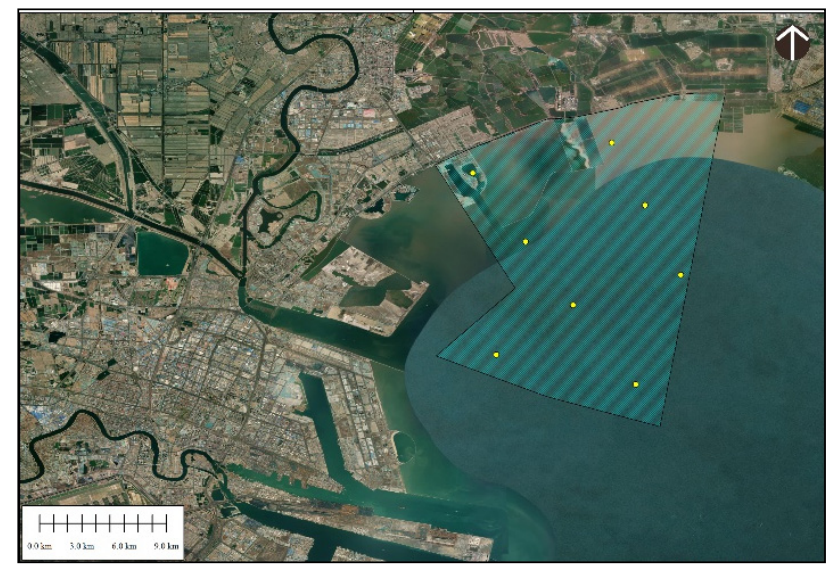

Fig. 3. Monitoring stations at 2017.

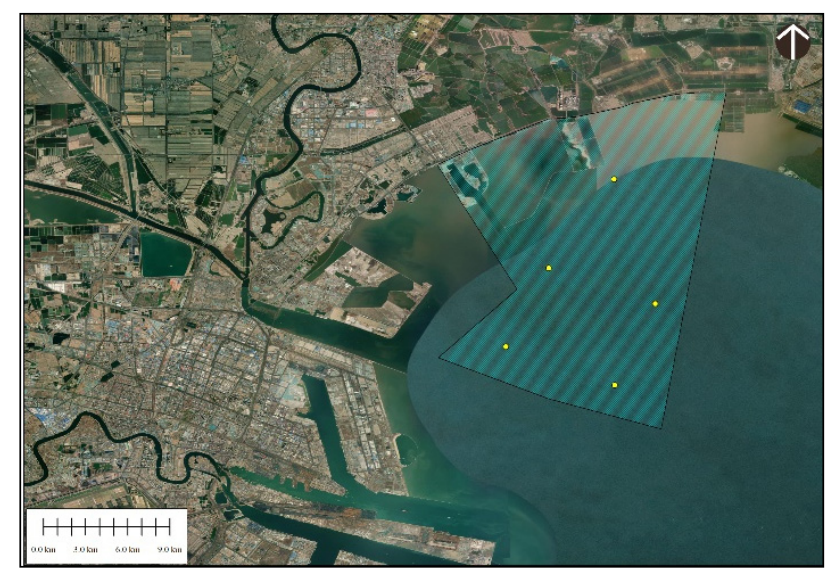

Fig. 4. Monitoring stations from 2018 to 2019

\subsection{Evaluation standard and method}

\subsubsection{Evaluation standard}

Adopt 《Sea water quality standard》 (GB 3097-1997) to evaluate COD, DIN and active phosphate.

Table 1. Sea water quality standard. Unit: $\mathrm{mg} / \mathrm{L}$

\begin{tabular}{|c|c|c|c|c|}
\hline Factor & Class I & Class II & Class III & $\begin{array}{c}\text { Class } \\
\text { IV }\end{array}$ \\
\hline $\mathrm{COD} \leq$ & 2 & 3 & 4 & 5 \\
\hline $\mathrm{DIN} \leq$ & 0.20 & 0.30 & 0.40 & 0.50 \\
\hline
\end{tabular}

\begin{tabular}{|c|c|c|c|c|}
\hline $\begin{array}{c}\text { Active } \\
\text { phosphate } \leq\end{array}$ & 0.015 & 0.030 & 0.030 & 0.045 \\
\hline
\end{tabular}

\subsubsection{Single-factor standard index method}

This paper use single-factor standard index method to evaluate COD, DIN and active phosphate. When the standard index value $\mathrm{Pi}$ is greater than 1 , it means that the evaluation factor exceeds its corresponding evaluation standard, that is, the factor cannot meet the marine function requirement of the evaluated sea area.

\subsubsection{Eutrophication evaluation method}

Using the eutrophication experience discriminant relationship published by the State Oceanic Administration: $\mathrm{E}=\mathrm{COD} * \mathrm{DIN} * \mathrm{DIP} * 106 / 4500$, DIN, DIP and COD represent the concentration of DIN, active phosphate and COD in seawater. For the evaluation of seawater eutrophication state, the definition of $E$ is used to divide seawater into 4 levels: $\mathrm{E} \geq 1$ means eutrophication, $1 \leq \mathrm{E} \leq 3$ means mild eutrophication, and $3<\mathrm{E} \leq 9$ means moderate eutrophication. $\mathrm{E}>9$ indicates severe eutrophication.

\subsubsection{The ratio of $N / P$}

The structure of nitrogen and phosphorus nutrients is expressed by the ratio of N/P. The growth of phytoplankton is directly related to the nutrients in seawater, and the content of nutrients will directly affect the growth of phytoplankton, thereby affecting the marine primary productivity. The higher nutrient content will easily lead to eutrophication, and the less nutrient content will restrict growth. Eutrophication will lead to the occurrence of red tides and harm marine biological resources and ecological environment. The normal N/P ratio is 16 , when the ratio is lower than 16 , indicating that the growth of algae is limited by nitrogen; while the N/P ratio is higher than 16 , indicating that it is limited by phosphorus.

\section{Trend analysis of seawater quality and eutrophication status}

The monitoring results of various factors in the seawater of Tianjin Hangu Agricultural and Fishery Zone from 2010 to 2019 are shown in Table 2.

Table 2. Monitoring results.

\begin{tabular}{|c|c|c|c|c|}
\hline \multirow{2}{*}{ Year } & \multicolumn{2}{|c|}{ COD } & \multicolumn{2}{c|}{ DIN } \\
\cline { 2 - 5 } & Range & $\begin{array}{c}\text { Avera } \\
\text { ge }\end{array}$ & Range & Average \\
\hline 2010 & $1.12 \sim 1.96$ & 1.628 & $0.512 \sim 0.847$ & 0.678 \\
\hline 2011 & $0.634 \sim 1.39$ & 0.912 & $0.459 \sim 0.502$ & 0.476 \\
\hline 2012 & $0.791 \sim 0.831$ & 0.811 & $0.4605 \sim 0.4824$ & 0.472 \\
\hline 2013 & $1.83 \sim 1.88$ & 1.855 & $0.2914 \sim 0.3213$ & 0.306 \\
\hline 2014 & $0.6-1.3$ & 0.78 & $0.2156 \sim 0.4939$ & 0.316 \\
\hline
\end{tabular}




\begin{tabular}{|c|c|c|c|c|}
\hline 2015 & $1.89 \sim 1.99$ & 1.956 & $0.1816 \sim 0.2556$ & 0.214 \\
\hline 2017 & $1.76 \sim 3.24$ & 2.45 & $0.03046 \sim 0.5671$ & 0.222 \\
\hline 2018 & $0.64 \sim 1.52$ & 0.944 & $0.09 \sim 0.31$ & 0.150 \\
\hline 2019 & $0.55 \sim 1.23$ & 0.854 & $0.132 \sim 0.282$ & 0.204 \\
\hline \multirow{2}{*}{ Year } & \multicolumn{3}{|c|}{ Active phosphate } \\
\cline { 2 - 4 } & \multicolumn{2}{|c|}{ Range } & Average \\
\hline 2010 & $0.00135 \sim 0.00539$ & 0.0030 \\
\hline 2011 & $0.0212 \sim 0.0281$ & 0.0247 \\
\hline 2012 & $0.0211 \sim 0.0225$ & 0.0218 \\
\hline 2013 & $0.00261 \sim 0.00337$ & 0.0030 \\
\hline 2014 & $0.00104 \sim 0.00331$ & 0.0020 \\
\hline 2015 & $0.0135 \sim 0.0175$ & 0.0148 \\
\hline 2017 & $0.00146 \sim 0.0211$ & 0.0059 \\
\hline 2018 & $0.00367 \sim 0.01806$ & 0.0079 \\
\hline 2019 & $0.0149 \sim 0.0327$ & 0.0228 \\
\hline
\end{tabular}

\subsection{COD}

According to Table 2, except for 2017, the COD content in the other years all meet the class I seawater quality standard, and COD content in 2017 can meet class III seawater quality standard. The variation trend of average COD content in the seawater of Tianjin Hangu Agricultural and Fishery Zone from 2010 to 2019 is shown in Figure 5. The COD content in 2019 is basically the same as that in 2011-2012. The overall COD content shows a fluctuating trend, and the COD content in the sea is relatively stable, which can basically meet the water quality requirement of the agricultural and fishery functional areas.

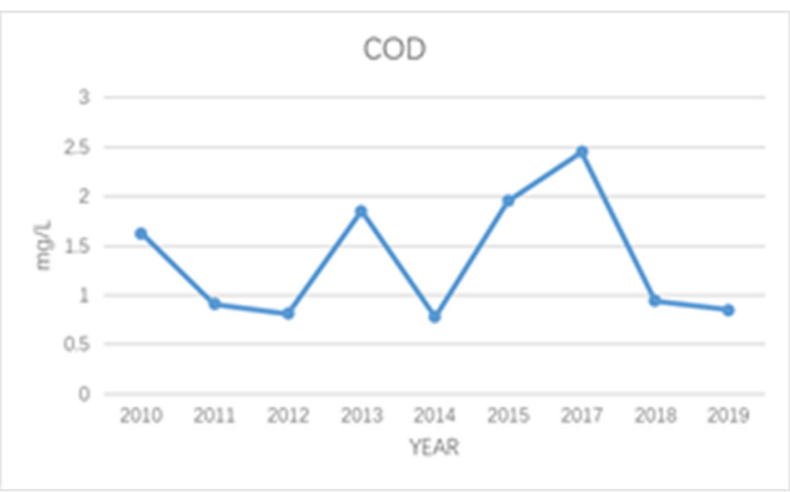

Fig. 5. COD content variation trend from 2010 to 2019 .

\subsection{DIN}

The variation trend of average DIN content in the seawater of Tianjin Hangu Agricultural and Fishery Zone from 2010 to 2019 is shown in Figure 6. The overall DIN content shows a downward trend. Compared with 2010, which the DIN content exceeds the class IV sea water quality standard, the DIN in the seawater from 2015 to 2019 can meet the class II sea water quality standard and the water quality requirement of its functional areas.

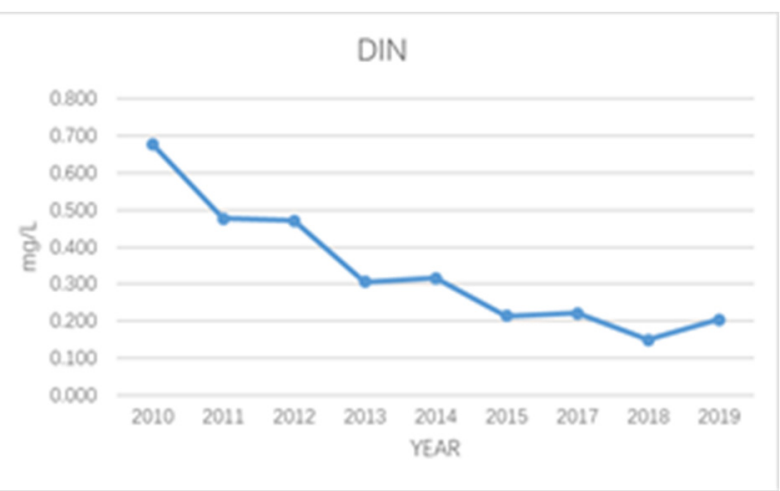

Fig. 6. DIN content variation trend from 2010 to 2019.

\subsection{Active phosphate}

The variation trend of average active phosphate content in the seawater of Tianjin Hangu Agricultural and Fishery Zone from 2010 to 2019 is shown in Figure 7. The overall active phosphate content shows a fluctuating trend, and it can basically meet the class II sea water quality standard. Although the active phosphate content has increased in 2019 compared with 2012-2018, it can also meet the class II standard and the water quality requirement of its functional areas.

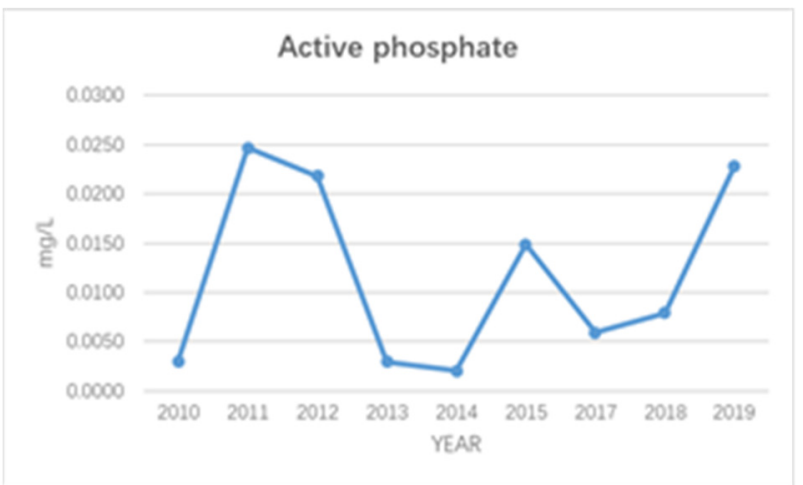

Fig. 7. Active phosphate content variation trend from 2010 to 2019.

\subsection{Eutrophication index(E)}

Table 3 shows the seawater eutrophication index (E) in Tianjin Hangu Agricultural and Fishery Zone from 2010 to 2019. The eutrophication in Tianjin Hangu Agricultural and Fishery Zone is not serious, only mild eutrophication occurred in 2011, 2012 and 2015.

Table 3. Eutrophication index (E) from 2010 to 2019.

\begin{tabular}{|c|c|c|}
\hline Year & E value & Rating \\
\hline 2010 & 0.743554 & No eutrophication \\
\hline 2011 & 2.378469 & mild eutrophication \\
\hline 2012 & 1.85245 & mild eutrophication \\
\hline 2013 & 0.37759 & No eutrophication \\
\hline 2014 & 0.111458 & No eutrophication \\
\hline 2015 & 1.378591 & mild eutrophication \\
\hline
\end{tabular}




\begin{tabular}{|l|l|l|}
\hline 2017 & 0.715646 & No eutrophication \\
\hline 2018 & 0.248775 & No eutrophication \\
\hline 2019 & 0.885977 & No eutrophication \\
\hline
\end{tabular}

\subsection{The ratio of N/P}

Table 4 shows the ratio of N/P in Tianjin Hangu Agricultural and Fishery Zone from 2010 to 2019. Except for 2015 and 2019, the rest of the year is always in the "phosphorus limit" state, that is, the N/P ratio is greater than 16.

Table 4. The ratio of N/P from 2010 to 2019.

\begin{tabular}{|c|c|l|}
\hline Year & The ratio of N/P & \multicolumn{1}{|c|}{ Rating } \\
\hline 2010 & 223.50 & phosphorus limit \\
\hline 2011 & 19.31 & phosphorus limit \\
\hline 2012 & 21.63 & phosphorus limit \\
\hline 2013 & 102.46 & phosphorus limit \\
\hline 2014 & 154.82 & phosphorus limit \\
\hline 2015 & 14.40 & nitrogen limit \\
\hline 2017 & 37.38 & phosphorus limit \\
\hline 2018 & 18.97 & phosphorus limit \\
\hline 2019 & 8.95 & nitrogen limit \\
\hline
\end{tabular}

\section{Results and discussion}

\subsection{Water quality evolution trend}

According to the trend analysis of COD, DIN and active phosphate content, the water quality of Tianjin Hangu Agricultural and Fishery Zone can basically meet the water quality requirements of the functional area. The content of COD and active phosphate shows a fluctuating trend, and the content of DIN shows a steady and improving trend. According to the "Tianjin Ecology and Environmental Statement" in recent 10 years, the water quality of rivers and coastal waters has shown an overall improvement trend, the results of this article are consistent with it.

According to the research results of Zheng Binghui, 1995 was the most serious year of DIN pollution in Beitangkou sea area from 1985 to 2003, DIN content exceeds the class IV sea water quality standard. After 1995, the DIN content declined, but it was still the most polluted area in Bohai Bay. In the past ten years, the water quality of Tianjin Hangu Agricultural and Fishery Zone has basically met the water quality requirements of the functional zone (Class II water quality standard), mainly due to the remarkable results in the cleaning and remediation of sewage outlets into the sea, the treatment of pollution from marine aquaculture, and the prevention and control of pollution from port ships.

\subsection{Nutrient structure evolution trend}

According to the research results of this article, the N/P ratio of Tianjin Hangu Agricultural and Fishery Zone shows that, except for 2015 and 2019, the rest of the year is always in the "phosphorus limit" state.

On the basis of the research results of Yu Zhigang et al. on the change trend of nutrient structure in the central Bohai Bay from 1982 to 1999 and Zheng Binghui et al. on the historical evolution of the source factors of nitrogen and phosphorus in the water quality of the Bohai Bay from 1985 to 2003, since the 1990s, the structure of nitrogen and phosphorus nutrients has changed from the "nitrogen limitation" in the 1980s to the "phosphorus limitation" in Tianjin coastal area, and the analysis results of this article are consistent with it. The "phosphorus restriction" state represents the relative lack of active phosphate in the sea area and the relative excess of DIN. P is the limiting factor for the growth of phytoplankton in the sea area. It shows that although the nitrogen content has been declining year by year in recent years and regional nitrogen pollution has been suppressed, the treatment of $\mathrm{N}$ pollution in sea areas is still urgent.

\subsection{Eutrophication evolution trend}

The eutrophication in Tianjin Hangu Agricultural and Fishery Zone is not serious. Only mild eutrophication occurred in 2011, 2012 and 2015. There has been no eutrophication in the past three years, and the eutrophication index of the sea area has shown a downward trend in recent years.

\section{Conclusions and recommendations}

In the past ten years, the cleaning and remediation of sewage outlets in the coastal waters of Tianjin, the pollution control of marine aquaculture, and the prevention and control of pollution from port ships have achieved remarkable results. The water quality of Tianjin Hangu Agricultural and Fishery Zone has basically met the water quality requirement of the functional area, regional nitrogen pollution suppressed, and the eutrophication index of the sea area has shown a downward trend year by year. However, Tianjin Hangu Agricultural and Fishery Area is located at the bottom of the Bohai Bay, which has poor seawater diffusion conditions, its unfavorable ocean hydrodynamic conditions may affect the transportation and diffusion of pollutants and causes severe fluctuations in water quality. In order to protect the sea water quality for agricultural and fishery functions, important aquatic germplasm resources and their habitats, pollution control and germplasm resource conservation in the sea still brook no delay.

\section{References}

1. Binghui Z, Yanwen Q, Wei M, et al. Historical Evolvement Trends of Nutrients in Waters of Bohai Bay from 1985 to 2003 [J].Environmental Science, 
2007, 28(3):494-499.

2. National Bureau of Quality and Technical Supervision. The specification for marine monitoring-Part 4: Seawater analysis (GB 17378.42007) [s], 2008.

3. National Environmental Protection Agency. Sea water quality standard (GB3097-1997) [s].

4. HUANG Ya-nan,WU Meng-meng. Application of eutrophication index in the coastal waters of China[J]. Marine Environmental Science, 2016, 35(2): 316-320.

5. Chu Fan, Liu Xianbin, Liu Zhanguang, et al. Evaluation of seawater eutrophication and principal component analysis in Tianjin coastal waters[J]. Ocean Bulletin, 2015, 34(001):107-112.

6. Zheng Binghui, Qin Yanwen, Meng Wei, et al. Analysis on the historical evolution trend of the source factors of nitrogen and phosphorus in the water quality of the Bohai Bay from 1985 to 2003[J]. Environmental Science, 2007

7. Yu Zhigang, Mi Tiezhu, Xie Baodong, et al. The evolution and interrelationship of the ecological environment parameters of the Bohai Sea in the past two decades[J]. Marine Environmental Science, 2000,19(1): 15 19 